\title{
Application of Priority Analysis: Smart City Community Complaint
}

\author{
Evaristus Didik Madyatmadja, Astari Karina Rahmah, Saphira Aretha Putri
}

\begin{abstract}
In this era of globalization that is happening right now, making developments in Information Technology that offers solutions to problems that occur in people's lives are important to improve available public services in the area. The development of Information Technology also gives innovation for government to improve existing public services and facilities. This report will discuss about application used by government in various regions in Indonesia in developing Smart City program that was initiated in 2014. Social Media is one of the ways and tools for community in Indonesia to give their aspiration, critic and response which aims for the improvement of government services and the development of Smart City so that they can meet the needs of the Community in their own regions. With this, responses from government is needed in accordance with the priority level of complaints given by the community through social media for the government to follow up their aspirations and complaints about the development of the Smart City.
\end{abstract}

Keywords: Smart City, Application, Complaints, Social Media, Decision Tree

\section{INTRODUCTION}

A s a country with one of the highest urbanization levels in the world and fourth in country with largest population in the world. Indonesia presents many internal challenges for the government in various regions that still trying to build a better country and cities in Indonesia and have an active community in it. Government must utilize integrated information and communication technology in all sectors of public services. The community expects much can be done for Indonesia to improve their living standards and welfare in every city in Indonesia. Therefore, cities in Indonesia especially city with a large population must become a Smart City [1].

With the current era of globalization that requires solutions using method and tools that do not require a complicated way to solve a problem and provide a useful solution, current

Revised Manuscript Received on December 30, 2019.

* Correspondence Author

Dr. Evaristus Didik Madyatmadja, Associate Professor, Information Systems, School of Information Systems, Bina Nusantara University, Jakarta. E-mail: emadyatmadja@binus.edu

Astari Karina Rahmah, Student, Information Systems Department, School of Information Systems, Bina Nusantara University, Jakarta. E-mail: astarikarina06@gmail.com

Saphira Aretha Putri, Student, Information Systems Department, School of Information Systems, Bina Nusantara University, Jakarta. E-mail: saphiraretha@gmail.com

(c) The Authors. Published by Blue Eyes Intelligence Engineering and Sciences Publication (BEIESP). This is an open access article under the CC BY-NC-ND license (http://creativecommons.org/licenses/by-nc-nd/4.0/) global population needs smart solution s that only use method that can solve one or more problems happened recently. It requires the ability to achieve the standard living desired by the community and responsible management of resources.

As a developing country that implementing Smart City for the first time, the public has complaints about the public services in Indonesia and the environment of a Smart City. The community has expectations for the government to solve the public services and environment problems quickly and accurately. However, the lack of response and communication from the government makes people uneasy and anxious about the complaints they give will be responded by the government or not [2].

By implementing smart solutions using Information Technology and Communication it will give the community important result in developing cities in Indonesia to be a Smart City. Basically, Information Technology and Communication can help to improve existing public services in Indonesia. A static, one-way websites were platforms where people could engage in transactional relationship with government such as filling out forms and paying bills [3]. The use of internet is also one of the ways for community to involve themselves in a government programs such as when people trying to open websites that are linked to government data to find useful information.

The internet in general and social media in an offer a plethora of possibilities for consumers, government and others to express their opinions and exchange information on organizations [4]. The development of internet that is very significant and concrete is the use of social media in a daily basis to seek and express public's opinion. The presence of social media in the era of globalization and in the governmental environment changes people's views of government, public bodies, and bureaucracy throughout the world. After several years of trial, testing and assessment of social media, the government aims to provide an overview how governments operate internally and how they interact with the public or the community outside the boundaries of government organizations [5]. This matters also a guide for government to use social media as a tool to communicate with community in every region in Indonesia. As a result, government starting to use Facebook as well as Twitter, Instagram, Email and website to gather the community complaints about problems in their area.

In its development, the government has a website that is only shown to provide information and websites that can be used by the public and community to get information about Smart City, which has been running since 2014. But the government didn't have a feature in the website for the community to speak out their complaints or aspirations for the government to resolve their problems. Since then, government provide a place that is social media for

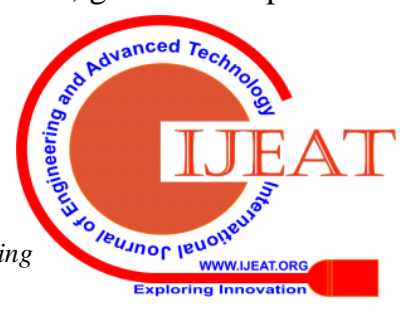


community to speak out the aspirations and problem in their area and how it needs the government help to resolve the problems to improve the city as a Smart City.

By sending their problems and aspirations, the community show their concern for the environment and convenience of their area. And, using social media as a way for government to communicate with the community the problems are done in real-time. If it's from Facebook, then the community will communicate with government by chatting via Messenger in real-time. By communicating with the community who have problems, social media can help government to improve and ease the performance of the government which can achieve effective governance. Through social media, the government is expected to provide better information and communication for the community so they can resolve the problem quickly and accurately. And, Smart City program can work well and positively, it also provides useful information for both community and government in their respective region.

\section{DEFINITION OF SMART CITY}

In this digital economy era, the urban area and the government should start to invest in the quality life of its people. Smart city is a concept with a broad idea that covers the aspects of resources, social and environment with the application of information technology.

According to [9], smart city is a municipal area that used the operational data, as it increased from a congestion in the city, and public safety events to optimize the operation of smart city public and private services. Main purpose of smart city is to improve the quality life of its citizen and create a more interesting, glory and greener city. To achieve these goals, Smart City Technology (SCT) is combined with the traditional city infrastructure. SCT aimed to every ICT that allows the city to utilize the large data sets and analyze it in order to be more connected and continuous. The concept of smart city appears for the last decade as the combination of ideas on how ICT can improve the city function, increase efficiency, raise competitiveness and provide new ways to solve poverty issues, social expropriation, and handle dilapidated environment [10].

Although, the terms of smart city have not been widely used in planning a literature report and municipal or urban studies, it is possible to identify various angles as a basis for further explanations. However, it should be remembered that in literature report, this term is not used holistically; but it is used by referring to various angles that distance it from smart cities as IT districts to smart cities in relation to the education (or intelligence) of their inhabitants. In relation to the economy, smart cities are used to describe cities with "smart" industries. This implies ICT industry as well as other organizations and industries that use Information and Communications Technology (ICT) in the production process, the "smart city" name is also used for business districts consist of organizations and companies in this field [11]. The term "smart city" is used to discuss the use of technology in this globalization era and everyday life. Not only includes ICT but also, and, modern transportation globalization and urban technology. Transportation and Logistics system are "smart" systems that increase municipal traffic and mobility of population. In addition, various questions that refer to the urban life in the city are always mentioned together in connection with the term of "smart city", such as security or safety, energy efficiency and sustainability. In short, there are several fields of activity described in the literature report in regard of the term smart city: industry of education, technical infrastructure, participation and various 'soft factors' [10].

\section{DEVELOPMENT OF SMART CITY}

For the last couple years and in the context of developing a economy digital, "smart city" agenda has achieved an actual momentum from European Union countries. Other international organization like OECD also enhance the agenda, take ICTs with the task of realizing strategic development of municipal or urban goals, such as continuity and improving the quality of community and citizen's life. Likewise, many cities in the world have used the term 'smart city' to describe themselves as well-endowed, prosperous and safe, in a variety of conditions and circumstances: for example, the Amsterdam Smart City initiative emphasizes the importance in collaborating with the businesses, government and communities so that they can save the energy by developing intelligent project that 'can change the world'. Southampton City Council uses smart city cards to emphasize the integrated electronic services importance in the industry; The Edinburgh City Council has established a vision of smart city around an important plan for the transformation of government; and Malta Smart City promoting business parks to promote sustainable economic growth. Oracle, Siemens and IBM have also shaped their smart city visions. Along this, several research projects and European Union policies also emerged to face the challenged posed by smart cities [12].

\section{E-COMPLAINT}

As a developing country, complaint from public are one way for the government to understand what is wanted and needed in the welfare of its people. Complaints are an input that gave the ability to courage increased public and media policy for dispute resolution. Meanwhile, based on business dictionary [13], complaint is a statement filed by the community or complainant to another party as respondent. The statement is based on recovering things and assets such as property or money. If seen from the point of view of communication, the complaint is active communication which can lead to interaction [14]. Generally, complaints can be defined as a commentary and explanation of dissatisfaction from the service and product by the community, customer or client. How can complaints be made effectively in decision making? Several organizations try to forecast the new challenges they will face in building new systems, thereby avoiding systems that cannot be accepted by users. However, it is obvious in forecasting all the challenge before it occurs and is not possible is because the user's acceptance of urban technology depends on a particular area [29]. In addition, the provincial government also needs feedback from users of the system which will be used as a tool to improve performance and development in the city that is being implemented as Smart City. The response received by the government from the community will be used to find out the next challenges that will be faced, user feedback can be considered as complaints and suggestions for the provincial government to improve public services and state facilities used by the community. 
E-government programs implementation programs specially e-complaints for communities and citizens can improve government operations internally and the quality of service delivery [15], [16]. Local governments can manage performance management measures specially the performance of services provision by providing infrastructure for management of performance [17]. Growth of e-complaint is helped by the introduction of companied that make customers want to express their opinions online. Consumers turn to site to register to do e-complaint in the number of records [18]. Complaints made online can help the government know what problems people are going through relating to the development of Jakarta Smart City that is being applied at this time.

\section{TEXT MINING}

Text mining refers as the process of collecting an enticing and significant patterns or knowledge from unstructured text documents. It is a continuation of data mining or knowledge discovery of databases [19].

Text mining is convinced to have a higher potential in collecting information than data mining, since there was a recent study found that $80 \%$ information of a company is contained in text documents [20]. The patterns of regular data mining are extracted from a structured database, on the other hand text mining pattern are extracted from natural language text. Databases are designed with a purpose to process programs automatically, in comparison, text is written so that people can read it. There are no programs that provide to read text and probably will not see that soon. We do not have programs that can "read" text and will not have such for the for seeable future. It will require a full simulation to see how the mind works before writing programs that read the way people read [21]. Database system regularly managed a structured data, while text data usually managed by search engine because of its lack of structure. A search engine allows users to get helpful information from a collection easily with a keyword query and improving the effectiveness and efficiency of search engine is the main topic in information retrieval field, where there are related topics that are also studied such as text categorization, summarization, text clustering and recommender systems [22].

\section{DECISION TREE}

Decision tree is defined as a classification procedure that recursive breaks down data sets into smaller subdivision based on a series of tests specified at each branch (or node) in the tree. Decision tree renowned as a way and techniques in making classification decision in pattern recognition. The priority in the fact that can maintain plentiful number of classes while simultaneously minimizing the time to make final decisions with a various of local decisions [23].

There are two types of decision tree that is based on the variable target, which are:

1. Categorical variable decision tree, which is a categorical target variable kind of decision tree.

2. Continuous variable decision tree, decision tree which has continuous target variable [24].

Decision tree offers many benefits for data mining, some of which are as follows:

1. Easy to understand for end users.

2. Can handle a variety of input data: Nominal, Numerical, and Textual.
3. Able to process incorrect datasets or missing values.

4. High performance and little effort.

5. Can be implemented data mining packages through

\section{NAÏVE BAYES}

Naïve Bayes classification that are based on the popular Bayes probability theorem, are known to create a model that is simple yet performed well, specially in the fields of document classification [39]. Naïve Bayes as well is a classification method that used probability and statistics method.

Naïve Bayes is one of the most effective and efficient method in data mining and to learn algorithm in machine learning. Naïve Bayes is the simplest method in the Bayesian theorem and network. The definition of conditional independence is all attributes are independent based on the given value of class variable [38].

Main characteristics of Naïve Bayes is a very strong assumption (naïve) of independence from each condition or event. The advantage of using Naïve Bayes is to determine parameters needed in the process, that it's only requires a small amount of training. It is assumed to be an independent variable, to determine classification is only needed the variance of a variable in a class, not the whole covariance matrix [39].

The stages of Naïve Bayes algorithm:

1. Count or the total of classes or tables

2. Count or the total the Number of Cases per Class

3. Multiply All of the Classes Variables

4. Compare the results by the class

The types of Naïve Bayes Classifier are [41]:

1. Multinomial Naïve Bayes

Mostly used for documents classification related problems. The predictors used by the classifier are the frequency of the words in the documents.

2. Bernoulli Naïve Bayes

It is similar to Multinomial Naïve Bayes, but the predictors are Boolean variables. Parameters used to predict the class variable takes up only values yes or no.

3. Gaussian Naïve Bayes

When the predictors take up a continuous value and not discrete, these values are sampled from Gaussian distribution.

\section{MIND FRAMEWORK}

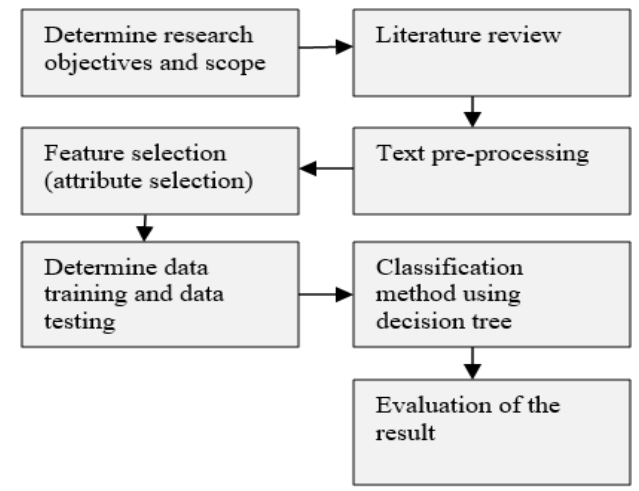

Published By: 
1. Determine research objectives and scope

Research objective requires the problem statement and summarize on what to achieve in a study. For an instance, if the identified problem is how slow the government actions toward public complaint, then the objective of this research is to identify the complaints priority and find a way to solve the problem.

The purpose of writing a research objective:

- Define the study focus that you will take

- Identify the variable measures

- Indicate a various step to be used

- Establish a study limit

- Avoid collecting any data that is not necessary [25].

\section{Literature review}

Literature review is a descriptive, analytic summary of the existing material relating to a particular topic or area of study. Literature review is a search and evaluation of literature needed in the research or selected topic area. This indicate the reader a deep understanding of the subject and the direction of the study.

Literature review has for main objectives:

- It defines the literature in your chosen field area

- It integrates the information in that literature into a summary.

- It analyzes the collected information by identifying gaps in recent knowledge; by showing the theories boundary and point of view; and formulize the areas for further research and reviewing the controversy areas.

- $\quad$ It provides the literature in an organized way [26]

3. Text pre-processing

Text pre-processing is a first stage of text mining in To put it another way, the text needs to be clean up to remove the unnecessary information, so it will be ready to analyze.

The following is the text pre-processing process:

a) Text cleanup

Text cleanup is removing and deleting any unwanted and unnecessary information such as removing advertisements from a web page, normalize text converted various formats, deal with figures, formats and formulas.

b) Tokenization

Tokenization achieved by splitting the punctuation marks and text on white spaces that don't belong to abbreviations identified in the steps.

c) Part of Speech Tagging

Part-of-Speech (POS) tagging is an assignment of word class. Input is received and given by the tokenization words and texts. Taggers must cope with unknown and unidentified word (OOV problem) and ambiguous mappings [27].

4. Selections of Feature

Selection of Feature known as variable and various selection, is the process of selecting a subset of important features that used for creation of model. The main opinion or presumption when using a technique selection of feature is that the data contain many irrelevant features and redundant data in it. order to prepare the text that will be proceed further.

Redundant data is the one that gives many extra information that unnecessary. Irrelevant data that gives no useful or relevant information with the topic. Selection of Feature technique is a subset of the general feature extraction field [28].

5. Determine data training and data testing

Data training is the observation in the training set from the experience uses by algorithm to learn. In supervised learning problems, every observation consists of an observed variable output and more observed variables input. Meanwhile, data testing is a set of observations that evaluate the performance of the model using performance metric. It's important that no observations from the set of training, it will be hard to evaluate or judge whether the algorithm has learned to generalize from the set of training or by simply memorizing it. [29].

6. Classification method using decision tree

Classification is a technique of data mining that involves three phases; learning, testing and application. A classifier is formed throughout the learning phase. It could be in classification rules, a decision tree, or a mathematical formula form. This is known as supervised learning since the label of the class on each training sample is provided.

A decision tree is a flowchart-like structure where each node indicated a test on the attribute. Each branch represents the test result and classes were represent as the leaf nodes. Testing attributes that contrary to the tree can be classified as unknown samples [30].

7. Evaluation of the result

This is the last phase where the researcher reviewing and evaluate the result of the research, whether it works, or it is not and to determines whether the program activities have been implemented as intended in the first place. Outcome from the evaluation will measures the effects in the target by assessing the progress in the outcomes or outcome objectives that the program achieves [37]. By doing Evaluation of the result it can help to identify areas for improvement and will help to realize and understand the goals more efficiently and accurately.

\section{PROBLEM IDENTIFICATION AND LEARNING OBJECTIVES}

The technology offered by smart cities is very diverse and is increasingly being used to improve public safety, from monitoring high crime areas to increasing emergency preparedness with Fritz Cam (Face Recognition). Smart city also brings efficiency to urban manufacturing and urban agriculture, including job creation, energy efficiency, space management and fresh goods for consumers [31].

Indonesia as a country that has a lot of population is certainly facing major problems such as security, the environment, employment, and public services. 
With so many problems, the community is often difficult to give their opinion because the government's response to the problem takes a long time. Therefore, many people expressed their complaints through social media platforms.

The challenge for the government is to increase public awareness in terms of promoting the use of smart city technology that has begun to be implemented in Indonesia and raising awareness of the benefits of building smart cities so that the mission objectives of the smart city itself can be achieved. The government must also be responsive in prioritizing public complaints that are included in social media. By doing so, this will facilitate the government in getting appreciation, opinions and complaints and fix problems that occur in the community and the environment around them.

The goal of the government's Smart City policy in Indonesia is to encourage local governments to use Information and Communication Technology (ICT) more broadly to improve their governance and decision-making processes. In the words of the president of the Republic of Indonesia, Jokowi, the aim was to encourage the development of 'citizen-centric' through e-governance [32].

With a significant increase in population in Indonesia can affect the welfare that occurs in several points of dense areas in Indonesia, especially Java. Environmental welfare also affects the condition of the people who live in the environment. If the environmental conditions inhabited by a community will continue to decline, then the welfare of the community will also decline which is likely to increase economic and environmental problems that occur.

Economic conditions in the community are also influenced by how the provincial government responds to complaints and wishes of the surrounding community. Good and best two-way communication between the government and citizens or communities will accelerate resolution of problems that have been complained by the community.

Problems that occur related to the use of social media platforms to improve and help build Indonesia to support smart cities in the region are the many requests and complaints that come in such as complains about rubbish, floods, damaged roads, traffic jams and security, written by Indonesian citizens related to the situation in the environment around them that disturbs the comfort of the environment and society. Therefore, several complaints were not submitted or were not carried out to address these complaints because the provincial government was unable to determine priorities for issues that were complained by the community in social media and the number of complaints made by the community. Based on the problem definition or learning problems that have been explained above, the learning objectives can be described as follows:

\section{General}

In General, the aim of provincial government to work together to build an integrated smart city is to find out the problem that occur in the community by making complaints and related photos around to achieve the mission that Indonesia is fully a country that upholds Smart City.

2. Special

To find out the priority of complaints or complaints from the Indonesian citizens through social media platforms using Decision Tree method.

Based on the learning objectives outlined, they can provide the following benefits:
1. The provincial government can determine priority issues that can be addressed directly.

2. Creating a good two-way relationship between the provincial government and the people of Indonesia.

3. Complaints data will be subjected to priority analysis to determine the funds and policies needed by each region.

\section{RESULT AND DISCUSSION}

Based on the result and analysis in this report and learning, to find the priority analysis from an e-complaint in Smart City Program, it can use Text Mining as a method to determine the priority as government of each region can follow up the problems and aspiration based on the priority analysis in the complaint result. Text Mining have a higher potential to collect the complaint information more than data mining because almost the information in a company or government is contained in text document. Based on this learning, two method can be obtained to find the priority analysis for complaint of smart city program, it can use Decision Tree and Naïve Bayes to find the priority complaint so the government can follow up with the source of the complaint. This learning discussed two methods above to find the priority complaint. Decision Tree and Naïve Bayes. The urgency of each problems of the complaint will be sorted by the most complaints received in one area and to resolve that issue Decision Tree and Naïve Bayes are two of the best methods to be use. The advantage of each methods is, for Decision Tree it is easy to understand because Decision Tree breaks down the data into smaller subdivision and specified each branch in the tree, it can also input variety of data such as numerical, nominal and textual, it generates a high performance with little effort. Whereas, the advantage of using Naïve Bayes is it is only requiring small amount of training, deal with missing values, sturdy for isolated noise points, fast and space efficiency. Based on the analysis, both methods are having an accurate result, so both are the best methods to find the priority complaints in Smart City.

\section{CONCLUSION}

Good two-way communication is the best way to provide an opinion calmly in order to meet the understanding that provides the best solution for a problem that occurs. Social media as a platform that bridges between the government and Indonesia citizens who deal directly with the surrounding issues. Based on the theory stated and described above, analysis of the level of complaints in social media can be carried out. Complaints about problems that occur in Indonesia that must be resolved by the provincial government as soon as possible. Due to the large number of complaints in social media, a way to increase the number of resolutions and management of funding and policy issues that can be done by the provincial government must be made to comfort the environment and the welfare of the people of Indonesia.

In this analysis, it can be seen that the way that can be done to solve problems quickly and responsively is to determine priority complaints, namely complaints about problems in the environment carried out by the people who get the highest level of complaints, then those problems must be worked out and responded first. 
By analyzing priority complaints, it can be concluded that the method that can be used and is the best method for solving this is the Decision Tree method due to the higher level of accuracy compared to other methods suitable for the use in this case. Naïve Bayes is a good method too for analyzing a priority analysis because of the simple method to use yet it has almost accurate result in the data. But the decision tree has a higher accuracy level than Naïve Bayes method. Because the higher the level of accuracy produced, the more similar the work produced after implementation in the field. With high accuracy results, the provincial government can make decisions in a responsive, precise and fast manner.

\section{REFERENCES}

1. Pemerintah Provinsi DKI Jakarta. (2019). Jakarta Smart City - Profil. Retrieved from Jakarta Smart City: http://interactive.smartcity.jakarta.go.id/

2. Madyatmadja, E.D., Olivia, J., \& Sunaryo, R. F. (2019). Priority Analysis Of Community Complaints Through E-Government Based On Social Media.

3. Zavattaro, S. M., French, P. E., \& Mohanty, S. D. (2015). A sentiment analysis of U.S. local government tweets: The connection between tone and citizen involvement.

4. Criado, J. I., Sandoval-Almazan, R., \& Gil-Garcia, J. R. (2013) Government innovation through social media. Government Information Quarterly

5. CNN Indonesia. (2019). Jakarta Smart City, Mimpi Era Ahok Atasi Masalah Ibu Kota. Retrieved from CNN Indonesia: https://www.cnnindonesia.com/teknologi/20190621194342-185-4054 23/jakarta-smart-city-mimpi-era-ahok-atasi-masalah-ibu-kota.

6. Einwiller, S. A., \& Steilen, S. (2015). Handling complaints on social network sites - An analysis of complaints and complaint responses on Facebook and Twitter pages of large US companies. (The Journey, n.d.)

7. Qlue berdampak positif bagi implementasi smart city, 2019

8. C. Harrison, B. Eckman, R. Hamilton, P. Hartswick, J.Kalagnanam, J. Paraszczak, and P. Williams, "Foundations for Smarter Cities," IBM J. Res. Dev., vol. 54, no. 4, pp. 1-16, Jul. 2010.

9. F. \&amp; Sullivan, "Frost \& Sullivan: Global Smart Cities market to reach US\$1.56 trillion by 2020." [Online]. Available: http://www.prnewswire.com/newsreleases/frost-

sullivan-global-smart-cities-market-toreach-us156-trillion-by-2020-30 0001531.html. [Accessed: 30-May-2016]

10. Lombardia, P., Giordanob, S., Farouh, H., \& Yousef, W. (2012). Modelling the smart city performance. Innovation-The European Journal of Social Science Research, 138.

11. Deakin, Mark. 2014. Smart Cities Governing, modelling, and analysing the transition. New York : Routledge, 2014.

12. Vector Data, 2012. [Online]. Available: https://grasswiki.osgeo.org/wiki/Vector_Data.

13. B. Dictionary, "Complaint." [Online]. Available: http://www.businessdictionary.com/ definition/complaint.html. [Accessed: 27-Nov-2016].

14. J. Davison and J. Grieves, "Why should local government show an interest in service quality," The TQM Magazine, vol. 8, no. 5, pp. 32-38, 1996

15. A. A. Rashid, H. Jusoh, and J. A. Malek, "Enhancing urban governance efficiency through the egovernment of Malaysian local authorities The case of Subang Jaya," GEOGRAFIA Online TM Malaysian Journal of Society and Space, vol. 6, issue. 1, pp. 1-12, 1996.

16. R. M. Ramli, "Malaysian e-government: issues and challenges in public administration," IPEDR, vol. 48, pp. 19-23, 2012.

17. Tyrrell, B., \& Woods, R. (2004). E-Complaint. Journal of Travel \& Tourism Marketing

18. Feldman, R. \& Dagan, I. (1995) Knowledge discovery in textual databases (KDT). In proceedings of the First International Conference on Knowledge Discovery and Data Mining (KDD-95), Montreal, Canada, August 20-21, AAAI Press, 112-117.

19. Tan, A.-H. (n.d.). Text Mining: The state of the art and the challenges.

20. Hearst, M. (2003). What Is Text Mining? California

21. Aggarwal, C. C. (2012). Mining Text Data. New York: Springer.

22. Decision Tree Classification of Land Cover from Remotely Sensed Data . Friedl, M. A. and Brodleyf, C. E. 1997. 1997.

23. Brid, Rajesh S. 2018. Introduction to Decision Tree. GreyAtom. [Online] October 2018, 2018 https://medium.com/greyatom/decision-trees-a-simple-way-to-visuali ze-a-decision-dc506a403aeb.
24. Research objectives. (n.d.). Retrieved from Open Learn create: https://www.open.edu/openlearncreate/mod/oucontent/view.php?id=2 31 \&section $=8.6 .2$

25. Literature reviews. (2019). Retrieved from Royal Literary Fund: https://www.rlf.org.uk/resources/what-is-a-literature-review/

26. TEXT MINING: CONCEPTS, PROCESS AND APPLICATIONS. (n.d.). Retrieved from Research \& Reviews: http://www.rroij.com/open-access/text-mining-concepts-process-andapplications-36-39.php?aid=38178

27. Training Data and Test Data. (n.d.). Retrieved from Tutorials Point: https://www.tutorialspoint.com/machine_learning_with_python/mach ine_learning_with_python_training_test_data.htm

28. Ding, Q., Ding, Q., \& Perrizo, W. (2002). Decision Tree Classification of Spatial Data Streams.

29. Rokach, Lior, and Oded Maimon. "DECISION TREES." 28. Web. 1 Feb. 2013.

30. Opinion Mining and Sentiment Analysis. Pang, Bo and Lee, Lillian. 2008. 2008.

31. Hirst, Graeme. 2012. Sentiment Analysis and Opinion Mining SYNTHESIS LECTURES ON HUMAN LANGUAGE TECHNOLOGIES. s.l. : Morgan \& Claypool, 2012.

32. Sentiment Analysis for Smart Cities: State of the Art and. Ahmed, Kaoutar Ben, et al. 2016. 2016, Int'l Conf. Internet Computing and Internet of Things | ICOMP'16 |, p. CA.

33. T. Nasukawa and J. Yi, "Sentiment analysis: Capturing favorability using natural language processing," in Proceedings of the 2 nd international conference on Knowledge capture, 2003, pp. 70-77.

34. INI MASALAH MENGAPA JAKARTA SULIT MENJADI SMART CITY. Elmecon Multikencana. [Online] http://elmecon-mk.com/article/ini-masalah-mengapa-jakarta-sulit-men jadi-smart-city/.

35. Jurriends, Edwin and Tapsell, Ross. 2017. Digital Indonesia connectivity and divergence. Singapore : ISEAS, 2017.

36. Najar, A. S., Al-Sukhni, H. A., \& Aghakhani, N. (2010). The Application of Service-Oriented Architecture in E-complaint System. 2010 Second International Conference on Communication Software and Networks.

37. CDC GOV. (n.d.). Types of Evaluation. Retrieved from CDC GOV: https://www.cdc.gov/std/Program/pupestd/Types\%20of\%20Evaluatio $\underline{\text { n.pdf }}$

38. INFORMATIKALOGI. (2017). Algoritma Naive Bayes. Retrieved from INFORMATIKALOGI: https://informatikalogi.com/algoritma-naive-bayes/

39. Raschka, S. (2014, 10 16). Naive Bayes and Text Classification I. Naive Bayes and Text Classification I - Introduction and Theory. Retrieved from Cornell University: https://arxiv.org/abs/1410.5329

40. Zhang, H. (n.d.). The Optimality of Naive Bayes. The Optimality of Naive Bayes. Retrieved from AAAI.

41. Gandhi, R. (2018). Naive Bayes Classifier. Retrieved from Towards

Science: https://towardsdatascience.com/naive-bayes-classifier-81d512f50a7c

\section{AUTHORS PROFILE}

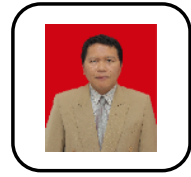

Evaristus Didik Madyatmadja received master's degree of Computer Science from University of Gadjah Mada (UGM), Yogyakarta, Indonesia, in 2005. He received the Doctor of Computer Science from Bina Nusantara University (Binus), Jakarta, Indonesia, in 2019. Currently, he is an Associate Professor at School of Information Systems, Bina Nusantara University, Jakarta, Indonesia. His interests are in e-government, decision support system, data mining and business intelligence.

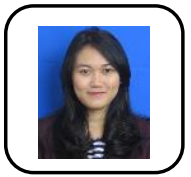

Astari Karina Rahmah is still in college to take her bachelor's degree in Information System at Bina Nusantara University. She currently an Intern at L'Oreal Indonesia. Her interests are in business intelligence and data mining. 
Saphira Aretha Putri is still in college to take her bachelor's degree in Information System at Bina Nusantara University. She currently an Intern at PT IBM Indonesia / PT Jasa Teknologi Informasi IBM. Her interests are business intelligence, text mining. 